\title{
USE OF HYDROGEN PEROXIDE AND PERCARBONATE TO TREAT CHLORINATED AROMATIC HYDROCARBON-CONTAMINATED SOIL
}

\author{
Marika Viisimaa, Anna Goi \\ Department of Chemical Engineering, Tallinn University of Technology, Ehitajate tee 5, 19086 Tallinn, \\ Estonia
}

Submitted 3 May 2012; accepted 9 May 2013

\begin{abstract}
This study compared treatment methods that utilised a liquid carrier of hydrogen peroxide and a solid carrier, percarbonate, for p-dichlorobenzene, p-chloro-m-cresol and p-chlorothymol degradation in the soil. The targeted chlorinated aromatic contaminants in the soil degraded to a certain level when treated with the liquid hydrogen peroxide, but the removal efficacy was not dependent on the dosage. In contrast, an increase in the percarbonate dosage enhanced the contaminant removal. Supplementary ferrous iron was more effective for the treatment that employed the liquid carrier of hydrogen peroxide than the treatment employing the solid carrier. Although acidic $\mathrm{pH}$ conditions (initial $\mathrm{pH}$ of 2.5) favoured contaminant degradation using liquid hydrogen peroxide, the treatment involving percarbonate resulted in more effective contaminant removal without any soil pH preadjustment. Therefore, the solid carrier of hydrogen peroxide, percarbonate, was concluded to be an effective alternative to the liquid carrier, resulting in greater contaminant removal at natural soil $\mathrm{pH}$ values.

Keywords: soil cleaning technologies, chemical oxidation, hydrogen peroxide carrier, activation aid.

Reference to this paper should be made as follows: Viisimaa, M.; Goi, A. 2014. Use of hydrogen peroxide and percarbonate to treat chlorinated aromatic hydrocarbon-contaminated soil, Journal of Environmental Engineering and Landscape Management 22(1): 30-39. http://dx.doi.org/10.3846/16486897.2013.804827
\end{abstract}

\section{Introduction}

Hydrogen peroxide is one of the most popular chemicals used for contaminated soil treatment by chemical oxidation (Watts, Teel 2006). Oxidation with hydrogen peroxide occurs mostly through the generation of free hydroxyl radicals, and the most widespread activator used for the radical pathway is ferrous iron. Hydrogen peroxide activated by ferrous iron is known (Barb et al. 1951) as a classical Fenton's reagent, while any deviation from the classical mixture is known as a modified Fenton system. The modified Fenton system has been used to overcome apparent disadvantages in the use of the classical system, including the costly acidic range needed to maintain the radical reactions and the hydroxyl radicals' non-productive consumption, and it is based on the fundamental principles of Fenton chemistry. However, this system may utilise the application of different concentrations of $\mathrm{H}_{2} \mathrm{O}_{2}$ (2-20\%) (Watts et al. 1999; Žukauskaitè et al. 2012) and carriers of hydrogen peroxide such as $\mathrm{CaO}_{2}$ (Arienzo 2000; Northup, Cassidy 2008; Goi et al. 2011), and it may use chelating agents such as EDTA in addition to transition metals (Sun, Pignatello 1992; Vicente et al. 2011). While Fenton's reagent system refers to the iron-mediated hydroxyl radical production from $\mathrm{H}_{2} \mathrm{O}_{2}$ decomposition, most soil transition metals and ion metals containing minerals (Watts et al. 1992) can also activate the hydrogen peroxide oxidation.

The application of sodium percarbonate, $\mathrm{Na}_{2} \mathrm{CO}_{3}$. $1.5 \mathrm{H}_{2} \mathrm{O}_{2}$ (hereafter referred to as percarbonate), is another way to modify the Fenton system. Cravotto et al. (2007) and Rivas et al. (2010) have reported that percarbonate is a solid carrier of hydrogen peroxide with the same features as the liquid carrier, but having safer handling and environmentally friendly procedures. Percarbonate is a crystalline chemical compound that readily dissolves in water, yielding hydrogen peroxide and sodium carbonate (Eq. 1) and creating an alkaline, oxidative environment as a result (McKillop, Sanderson 1995). The actual name of this chemical compound, which reflects the structure of this chemical, is carbonate perhydrate (McKillop, Sanderson 1995).

$$
2\left(\mathrm{Na}_{2} \mathrm{CO}_{3} \bullet 1.5 \mathrm{H}_{2} \mathrm{O}_{2}\right) \rightarrow 2 \mathrm{Na}_{2} \mathrm{CO}_{3}+3 \mathrm{H}_{2} \mathrm{O}_{2} \text {. }
$$

It is believed (Rivas et al. 2010; McKillop, Sanderson 1995) that the dominant chemistry of the percarbonate oxidation system is that of hydrogen peroxide. Released hydrogen peroxide can oxidise contaminants through the 
formation of hydroxyl radicals or any other oxidative species and is also decomposed to water and oxygen (Eq. 2 ). Due to the oxygen formation, percarbonate is also used (Vesper et al. 1994) to support the aerobic biodegradation of contaminants.

$$
2 \mathrm{H}_{2} \mathrm{O}_{2} \rightarrow 2 \mathrm{H}_{2} \mathrm{O}+\mathrm{O}_{2} .
$$

The sodium carbonate formed in Eq. 1 gives a basic reaction of the carbonate ion hydrolysis in water:

$$
\begin{gathered}
\mathrm{CO}_{3}^{2-}+\mathrm{H}_{2} \mathrm{O} \rightarrow \mathrm{HCO}_{3}^{-}+\mathrm{OH}^{-} ; \\
\mathrm{HCO}_{3}^{-} \leftrightarrow \mathrm{CO}_{3}^{2-}+\mathrm{H}^{+} .
\end{gathered}
$$

Rivas et al. (2010) have stated that the only potential drawback of $\mathrm{Na}_{2} \mathrm{CO}_{3} \cdot 1.5 \mathrm{H}_{2} \mathrm{O}_{2}$ could be the scavenging of hydroxyl radicals (Eqs 5-7) exerted by the release of (bi)carbonate anions (Eqs 3 and 4). Due to this scavenging, it is believed (Ku et al. 1996; Glaze et al. 1995) that (bi)carbonate anions have an overall negative impact on the treatment efficacy.

$$
\begin{gathered}
\mathrm{HCO}_{3}^{-}+\mathrm{OH}^{\bullet} \rightarrow \mathrm{HCO}_{3}^{\bullet}+\mathrm{OH}^{-} \\
\mathrm{HCO}_{3}^{\bullet} \leftrightarrow \mathrm{H}^{+}+\mathrm{CO}_{3}^{-\bullet} \\
\mathrm{CO}_{3}^{2-}+\mathrm{OH}^{\bullet} \rightarrow \mathrm{CO}_{3}^{-\bullet}+\mathrm{OH}^{-} .
\end{gathered}
$$

However, the carbonate radical anions $\left(\mathrm{CO}_{3}^{-}\right)$ generated by reactions 6 and 7 (Umschlag, Hermann 1999) have been reported to yield a reduction potential $\left(\mathrm{CO}_{3}^{-}, \mathrm{H}^{+} / \mathrm{HCO}_{3}^{-}\right.$) of $1.63 \mathrm{~V}$ at $\mathrm{pH} 8.4$ (Zuo et al. 1999) and have been found (Umschlag, Hermann 1999) to be effective for the degradation of various aromatic compounds, such as benzene, p-xylene, toluene, chlorobenzene, nitrobenzene and benzonitrile. In addition, it has been found (Flangan et al. 1986) that bicarbonate anions can also react with hydrogen peroxide to generate peroxymonocarbonate ions $\left(\mathrm{HCO}_{4}^{-}\right)$(Eq. 8) with an estimated redox potential of $1.8 \mathrm{~V}$ (Yao, Richardson 2000) and several other active oxygen species, such as superoxide ions $\left(\mathrm{O}_{2}^{-}\right)$and singlet oxygen $\left({ }^{1} \mathrm{O}_{2}\right)$.

$$
\mathrm{HCO}_{3}^{-}+\mathrm{H}_{2} \mathrm{O}_{2} \rightarrow \mathrm{HCO}_{4}^{-}+\mathrm{H}_{2} \mathrm{O} \text {. }
$$

A bicarbonate-activated hydrogen peroxide system has been found (Flangan et al. 1986; Yao, Richardson 2000; Regino, Richardson 2007) to be capable of oxidising of a variety of organic compounds in the liquid phase. Moreover, the reactivity of $\mathrm{HCO}_{4}^{-}$towards organic sulphides has been found (Regino, Richardson 2007) to be higher than that of $\mathrm{H}_{2} \mathrm{O}_{2}$ by a factor of $100-500$ depending on the specific substrates. Thus, the chemistry of the percarbonate oxidation system is more complicated than previously suggested and may allow for the destruction of a wide range of resistant contaminants in soil and water.

There has been only one published study (Cravotto et al. 2007) on the application of percarbonate to contaminated soil treatment. This study combined sodium percarbonate and microwaves, resulting in the complete degradation of the aromatic compounds (4-chloronaphtol and 2,4-dichlorophenoxyacetic acid) in the soil. However, unaccompanied applications of microwaves and ultrasound (Duong et al. 2010) also had the potential to degrade chlororganic contaminants in soil. As a result, there are no significant studies comparing the efficacy of contaminated soil treatment methods that utilise an unaccompanied solid hydrogen peroxide carrier (percarbonate) and a liquid carrier (hydrogen peroxide).

Chlorobenzenes (CBs) are used in engine-block cleaners, solvents, pesticides, pharmaceutical intermediates and for the synthesis of chlorophenols and disinfectants. Chlorothymols (CTh) are applied as effective fungicide components and chlorocresols $(\mathrm{CCr})$ can be found in metalworking fluids, pharmaceutical products and agricultural pesticides. The extensive use of these compounds has led to their substantial release into the environment (GomezBelinchon et al. 1991; Jan et al. 1994; Kot-Wasik et al. 2003; Feidieker et al. 1994), necessitating effective treatment methods. The application of liquid hydrogen peroxide has been found (Watts et al. 1997, 2008) to be effective for CB-contaminated soil treatment, indicating the need to test the solid hydrogen peroxide carrier, percarbonate, as a potential alternative to the liquid carrier. Although it is known that CBs can degrade in the presence of hydrogen peroxide in soil (Watts et al. 2008), the degradation efficacy of CBs, CCr and CTh when utilising hydrogen peroxide in the presence of carbonates/bicarbonates has not been studied.

Therefore, this study performed a comparative assessment of the treatment methods utilising percarbonate and liquid hydrogen peroxide for $\mathrm{p}$ dichlorobenzene ( $\mathrm{p}$-DCB), $\mathrm{p}$-chloro-m-cresol ( $\mathrm{p}-\mathrm{C}-\mathrm{m}$ $\mathrm{Cr}$ ) and p-chlorothymol (p-CTh) removal in soil. The testing of certain activation aids was executed $(\mathrm{pH}$ preadjustment and supplemental ferrous iron addition) because the activator efficiency depends not only on the target contaminant but also on the remedial chemical used. The influence of chemical dosage on the degradation of selected chlorinated aromatic contaminants was also studied.

\section{Methods}

\subsection{Soil characterisation}

Natural topsoil $(0-20 \mathrm{~cm})$ was dried overnight at $30^{\circ} \mathrm{C}$ in a circulating air drying oven before being spiked and sieved through a 2.0-mm sieve using a Retsch (AS 200) digital sieve shaker. Several characteristics of the soil are presented in Table 1. The soil $\mathrm{pH}$ was measured according to EPA method 9045C (1995) using a digital pH meter (CG-840, Schott) equipped with a Mettler Toledo InLaB 412 electrode. The total extractable iron 
Table 1. Soil properties

\begin{tabular}{ll}
\hline Parameter (unit) & $\begin{array}{c}\text { Value (mean } \pm \text { standard } \\
\text { deviation) }\end{array}$ \\
\hline $\mathrm{pH}$ & 5.8 \\
Ferrous iron (g kg & $1.9 \pm 0.5$ \\
Total extractable iron & $12.1 \pm 0.9$ \\
$\quad\left(\mathrm{~g} \mathrm{~kg}^{-1}\right.$ of soil) & \\
Ion-exchangeable Fe(II) & $2.0 \pm 0.3$ \\
$\quad$ fraction (mg kg of soil) $^{-1}$ & \\
Organic carbon (mg kg & \\
$\quad$ of soil) & $460 \pm 30$ \\
Sand (\%) & \\
Silt (\%) & 45.5 \\
Clay (\%) & 52 \\
\hline
\end{tabular}

in the soil was extracted using the method in Heron et al. (1994). Ferrous iron and the ion-exchangeable $\mathrm{Fe}(\mathrm{II})$ fraction were extracted according to the procedure presented by Tessier et al. (1979) and the iron in the extracts was measured photometrically at $492 \mathrm{~nm}$ using the phenanthroline method (Merck 1974). The soil's organic carbon was determined using sulphochromic oxidation (ISO 14235 1998) and the texture of the soil was identified as sandy silt. The soil identification was based on the principles established by ISO 14688-1, 2 (2002, 2004) using a laser scattering particle size distribution analyser (LA-950, Horiba).

The initial concentrations of each individual contaminant in the soil were $0.77 \pm 0.03 \mathrm{~g} \mathrm{p}$-DCB kg-1 of soil, $0.59 \pm 0.06 \mathrm{~g} \mathrm{p}-\mathrm{C}-\mathrm{m}-\mathrm{Cr} \mathrm{kg}{ }^{-1}$ of soil and $2.50 \pm$ $0.14 \mathrm{~g} \mathrm{p}-\mathrm{CTh} \mathrm{kg}^{-1}$ of soil. Thus, the total concentration of $\mathrm{p}-\mathrm{DCB}, \mathrm{p}-\mathrm{C}-\mathrm{m}-\mathrm{Cr}$ and $\mathrm{p}-\mathrm{CTh}$ in the untreated soil was $3.86 \pm 0.08 \mathrm{~g} \mathrm{~kg}^{-1}$ of soil. The initial concentrations of each target compound were verified by the GC-FID analysis of six replicates.

\subsection{Soil treatment}

Sodium percarbonate $\left(\mathrm{Na}_{2} \mathrm{CO}_{3} \cdot 1.5 \mathrm{H}_{2} \mathrm{O}_{2}\right.$, powder $)$ and hydrogen peroxide $(35 \%)$ were obtained from Aldrich for this experiment. The comparative assessment of the treatment methods' efficacy when utilising percarbonate and liquid $\mathrm{H}_{2} \mathrm{O}_{2}$ for the removal of chlorinated hydrocarbons, p-DCB, p-C-m-Cr and p-CTh, was performed by applying similar dosages of $\mathrm{H}_{2} \mathrm{O}_{2}$. The concentration of $\mathrm{H}_{2} \mathrm{O}_{2}$ was photometrically verified at $254 \mathrm{~nm}$ and the molar extinction coefficient for the hydrogen peroxide at $254 \mathrm{~nm}$ taken for the calculation of the $\mathrm{H}_{2} \mathrm{O}_{2}$ concentration was $19.6 \mathrm{M}^{-1}$ $\mathrm{cm}^{-1}$ (Baxendale, Wilson 1957). In the experiments using a supplemental activator addition, $\mathrm{FeSO}_{4} \cdot 7 \mathrm{H}_{2} \mathrm{O}$ salt (solution) was used as a ferrous iron source. The ferrous iron concentration in the stock solution was photometrically verified at $492 \mathrm{~nm}$ using the complex reaction with 1,10-phenanthrolinium chloride (Merck 1974).

The treatment of p-DCB-, p-C-m-Cr- and p-CThcontaminated soil with different chemical/contaminant weight (w/w) ratios was carried out in batch mode. The standard procedure entailed a slurry of $10 \mathrm{~g}$ soil with $10 \mathrm{~mL}$ of liquid (bi-distilled water and remedial chemical solution) being treated in a $0.2-\mathrm{L}$ cylindrical glass reactor using vigorous (300 rpm) magnetic stirring. The treatment time of $24 \mathrm{~h}$ was selected to ensure the complete decomposition of hydrogen peroxide. There was no residual hydrogen peroxide after $24 \mathrm{~h}$ of treatment. The flasks were sealed with a laboratory film (Parafilm) to reduce volatilisation losses. In the experiments using metal ion-activated hydrogen peroxide oxidation, ferrous iron solution was added and the reaction was initiated by a single addition of the chemical (hydrogen peroxide or percarbonate) solution. The soil was treated without $\mathrm{pH}$ pre-adjustment. In the experiments testing the $\mathrm{pH}$ effect on the treatment performance, the $\mathrm{pH}$ of the soil slurry was pre-adjusted to a value of 2.5 using $\mathrm{H}_{2} \mathrm{SO}_{4}$.

All of the experiments were carried out at $20 \pm 1{ }^{\circ} \mathrm{C}$ and in triplicate.

\subsection{Extraction and determination of contaminants}

The solid and liquid phases were not separated after treatment. Ten $\mathrm{mL}$ of hexane were added to the slurry and left overnight on an orbital shaker. Next, a vortex (Genius3, IKA) extraction procedure was employed two times (with $10 \mathrm{~mL}$ of $\mathrm{n}$-hexane) for $2 \mathrm{~min}$ each. Concentrated hexane extracts were mixed (1/1) with the internal standard, which was $\mathrm{C}_{16} \mathrm{H}_{34}$ dissolved in $\mathrm{n}$ hexane with a concentration of $0.235 \mathrm{~g} \mathrm{~L}^{-1}$. The measurement of the contaminant concentration in the extracts was performed using a gas chromatograph (FocusGC, Finnigan, Thermo Electron Corporation) with a flame-ionisation detector (GC-FID). $2 \mu \mathrm{L}$ of the extract were injected in a crossbond $100 \%$ dimethylpolysiloxane capillary column RTX-1 $\quad(30.0 \quad \mathrm{~m} \times$ $320 \mu \mathrm{m}$ id $\times 0.25 \mu \mathrm{m}$ film thickness) at an injector temperature of $260{ }^{\circ} \mathrm{C}$. The GC-FID temperature program included the following steps. The initial temperature was held at $50{ }^{\circ} \mathrm{C}$ for $1 \mathrm{~min}$ and then increased at a rate of $8{ }^{\circ} \mathrm{C} \mathrm{min}{ }^{-1}$ to $200{ }^{\circ} \mathrm{C}$ with a 3-min hold. The detector temperature was $330{ }^{\circ} \mathrm{C}$ and a splitless injection mode was used. The velocity of the carrier gas (nitrogen) was $1 \mathrm{~mL} \min ^{-1}$ and the coefficient of variation for the GC-FID method was $1.5 \%$. The external standard was prepared by dissolving $\mathrm{p}-\mathrm{DCB}, \mathrm{p}-\mathrm{C}-\mathrm{m}-\mathrm{Cr}$ and $\mathrm{p}-\mathrm{CTh}$ in n-hexane, and the method's detection limit was $11.3 \mathrm{mg}$ p-DCB, $9.0 \mathrm{mg} \mathrm{p}-\mathrm{C}-\mathrm{m}-\mathrm{Cr}$ and $7.8 \mathrm{mg} \mathrm{p}-\mathrm{CTh}$ per $\mathrm{L}$ of solvent, which corresponded to $34 \mathrm{mg}$ p-DCB, $27 \mathrm{mg} \mathrm{p}-\mathrm{C}-\mathrm{m}-\mathrm{Cr}$ and $26 \mathrm{mg}$ p-CTh per $\mathrm{kg}$ of soil. The GC-FID analyses 
of the un-spiked soil showed no indication of contaminants.

\subsection{Soil filtrate analyses}

The residual hydrogen peroxide in the soil filtrate treated by titanium sulphate with pertitanic acid formation was determined photometrically at $410 \mathrm{~nm}$ (Eisenberg 1943). The $\mathrm{pH}$ after the treatment was measured according to EPA method 9045C (1995). The ion content in the soil filtrate was measured using an ion chromatograph (761 Compact IC, Metrohm) equipped with a suppressed conductivity detector and a Metrosep A Supp $5(150 \mathrm{~mm} \times 4.0 \mathrm{~mm}$ id $)$ analytical column.

\section{Results and discussion}

\subsection{Removal of contaminants with the non-supplemented hydrogen peroxide treatment}

$\mathrm{p}-\mathrm{DCB}, \mathrm{p}-\mathrm{C}-\mathrm{m}-\mathrm{Cr}$ and $\mathrm{p}-\mathrm{CTh}$ in soil degraded with the addition of hydrogen peroxide only (Fig. 1), indicating the ability of the natural activators present in soil to activate the oxidation. The potential for naturally occurring minerals in the soil and some transition metals to activate the hydrogen peroxide oxidation process has been indicated in several previous studies (Matta et al. 2008; Watts et al. 1997; Kong et al. 1998; Teel et al. 2001). Nevertheless, the degradation of the contaminants in the soil with liquid hydrogen peroxide was uncompleted, resulting in the same level of contaminant removal regardless of the chemical dosage used (Fig. 1). The removal of p-DCB, p-C-m-Cr and $\mathrm{p}-\mathrm{CTh}$ with the liquid carrier averaged $10.1 \pm 0.7 \%$ of the $0.77 \pm 0.03 \mathrm{~g}$ of $\mathrm{p}-\mathrm{DCB}, 5.9 \pm 0.9 \%$ of the $0.59 \pm$ $0.06 \mathrm{~g}$ of $\mathrm{p}-\mathrm{C}-\mathrm{m}-\mathrm{Cr}$ and $22.7 \pm 0.8 \%$ of the $2.50 \pm 0.14 \mathrm{~g}$ of $\mathrm{p}-\mathrm{CTh}$ targeted in each $\mathrm{kg}$ of soil.

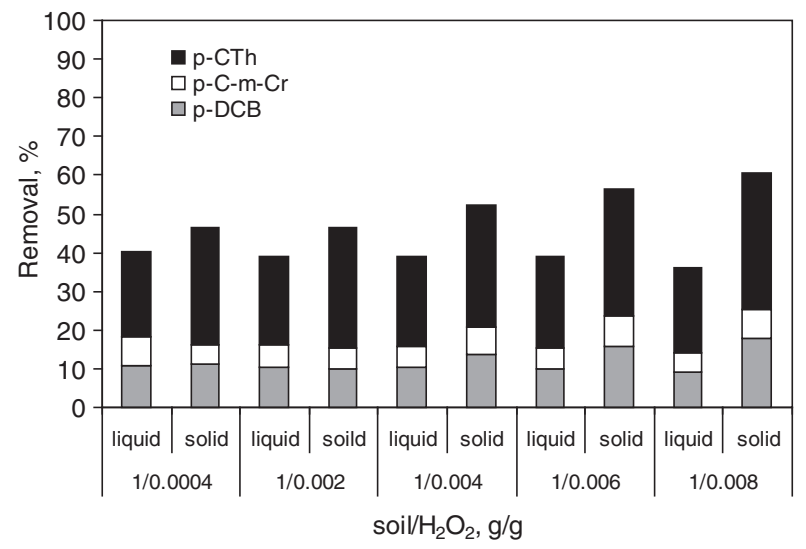

Fig. 1. p-DCB, p-C-m-Cr, and p-CTh removal ( $\%$ of initial content) in the soil after a 24-h treatment with liquid hydrogen peroxide and percarbonate, without the addition of supplemental ferrous iron and utilising different weight ratios of soil to $\mathrm{H}_{2} \mathrm{O}_{2}$
A lack of available activators in soil may limit the effective production of hydroxyl radicals and could be a reason for the oxidation reaction termination. The loss of the hydrogen peroxide without the degradation of the contaminants could be explained by competing reactions, such as non-productive chemical decomposition without the generation of oxidants, reaction with the soil's organic matter, etc. (Watts, Teel 2006).

Although the treatment with percarbonate in a study by Rivas et al. (2010) has indicated that metoprolol in aqueous solution has the same oxidising power as the liquid hydrogen peroxide, a 24-h soil treatment with percarbonate in the present study led to the improved degradation of p-DCB, p-C-m-Cr and p-CTh compared to that obtained by the treatment with liquid hydrogen peroxide (Fig. 1). The soil treatment with percarbonate at soil/hydrogen peroxide ratios ranging from $1 / 0.0004$ to $1 / 0.008$ allowed for the removal of $10-18 \%$ of p-DCB, $5-7 \%$ of p-C-m-Cr and $30-36 \%$ of p-CTh. Thus, some increase in the removal of each targeted compound was obtained with the application of percarbonate.

The contaminants removal by the percarbonate treatment increased somewhat as the percarbonate dosage increased (Fig. 1). This scenario assumed that several other reactions besides the hydrogen peroxide oxidation were able to proceed. For example, in a study by Regino and Richardson (2007), kinetic and spectroscopic studies of the bicarbonate-catalysed oxidation of organic sulphides have strongly supported the role of peroxymonocarbonate $\left(\mathrm{HCO}_{4}^{-}\right)$as the oxidant in bicarbonate-activated hydrogen peroxide solution. In a study by Xu et al. (2011), bicarbonate anions have also been identified as efficient activators of the hydrogen peroxide oxidation of some organic pollutants, including 4-chlorophenol, providing an efficient transitionmetal-free treatment method.

Moreover, certain chemical-physical properties (hydrophobicity, pKa) of the studied compounds, caused primarily by their aromatic nature and functional groups attached to the ring (Table 2), may also have influenced the efficacy. $\mathrm{CCr}$ and $\mathrm{CTh}$ are weak acids, and their solubility to polar solvents (water) is higher in basic conditions when they are dissociated. The $\mathrm{pH}$ increase (Table 3) with the rise in the percarbonate dosage could have resulted in the increased solubility of the target contaminants, which may have influenced the efficacy of the treatment. Increased solubility results in the increased availability of the contaminant to the oxidant, as it is known (Miller, Valentine 1999) that the oxidation reactions proceed mainly in the liquid phase.

The reactivity of the compounds to both applied chemicals followed the order $\mathrm{p}-\mathrm{C}-\mathrm{m}-\mathrm{Cr}<\mathrm{p}-\mathrm{DCB}<\mathrm{p}$ $\mathrm{CTh}$, which could be explained by their chemical structure that influence the rate of oxidizing species attack on the ring, chemical-physical properties of the 
Table 2. Chemical-physical properties (molecular weight, water solubility, $\log \mathrm{K}_{\mathrm{ow}}$ and $\mathrm{pK}_{\mathrm{a}}$ ) of the target compounds

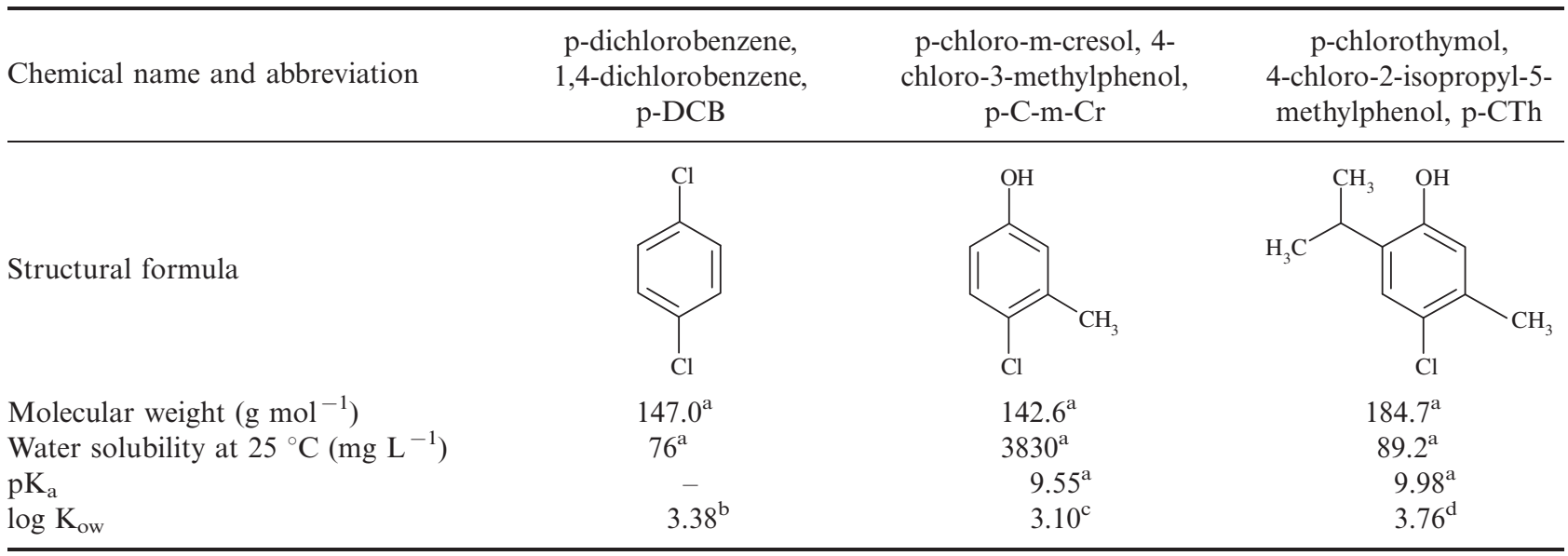

${ }^{\text {a }}$ Howard et al. (1997)

b Mackay and Boethling (2000)

${ }^{c}$ Wilfried (2005)

${ }^{\mathrm{d}}$ Finizio et al. (1997)

contaminants (Table 2) and the difference in the initial concentrations of the target compounds that were also known to have a strong influence on the efficacy of contaminant removal during the Fenton treatment.

\subsection{Removal of contaminants with the ferrous iron-supplemented hydrogen peroxide treatment}

Higher contaminants degradations, compared to those obtained by unaccompanied liquid hydrogen peroxide, were achieved with the addition of supplemental ferrous iron (Fig. 2a), suggesting a lack of available activators. The increasing $\mathrm{Fe}^{2+} / \mathrm{H}_{2} \mathrm{O}_{2}$ weight ratio, from $0.05 / 1$ to $0.3 / 1$ at lower dosages of liquid hydrogen peroxide (contaminant $/ \mathrm{H}_{2} \mathrm{O}_{2}=1 / 0.1, \mathrm{~g} / \mathrm{g}$ ), did not improve the degradation and even diminished the contaminant removal in the soil (Fig. 2a). This effect was explained by the excessive iron that provided conditions for the increased quenching of oxidising

Table 3. $\mathrm{pH}$ values of the soil slurry after $24 \mathrm{~h}$ of treatment with liquid hydrogen peroxide and percarbonate, with and without a supplemental ferrous iron addition

Contaminant $/ \mathrm{H}_{2} \mathrm{O}_{2} / \mathrm{Fe}^{2+}$, $\mathrm{w} / \mathrm{w} / \mathrm{w}$ $\mathrm{pH}$ after $24 \mathrm{~h}$ of treatment

Liquid hydrogen peroxide

$1 / 0.1 / 0 \quad 5.8$

$\begin{array}{ll}1 / 0.1 / 0.005 & 5.7\end{array}$

$1 / 2 / 0 \quad 4.9$

$1 / 2 / 0.1$

Percarbonate

$1 / 0.1 / 0 \quad 6.2$

$1 / 0.1 / 0.01 \quad 5.6$

$1 / 1 / 0 \quad 8.5$

$1 / 1 / 0.1$ agents (Eq. 9) (Barb et al. 1951), reducing the contaminant degradation efficacy as a result.

$$
\mathrm{Fe}^{2+}+\mathrm{OH}^{\bullet} \rightarrow \mathrm{Fe}^{3+}+\mathrm{OH}^{-}
$$

The increase in the supplemental activator/hydrogen peroxide ratio from $0.05 / 1$ to $0.2 / 1$ at a higher (contaminant $/ \mathrm{H}_{2} \mathrm{O}_{2}=1 / 2, \mathrm{~g} / \mathrm{g}$ ) dosage of hydrogen peroxide improved the degradation of the contaminants from $51.3 \pm 3.3$ to $73.2 \pm 1.8 \%$, respectively. The supplemental ferrous iron addition had a similar effect on the removal of the contaminants during the soil treatment with percarbonate (Fig. 2b). While the increase in the $\mathrm{Fe}^{2+} / \mathrm{H}_{2} \mathrm{O}_{2}$ ratio at a lower ratio of contaminant $/ \mathrm{H}_{2} \mathrm{O}_{2}=1 / 0.1$ (w/w) did not improve the degradation, the increase in that ratio at a higher ratio of contaminant $/ \mathrm{H}_{2} \mathrm{O}_{2}=1 / 1 \quad(\mathrm{w} / \mathrm{w})$ considerably increased the removal efficacy. The changes in the contaminant removal efficacy with the addition of the ferrous iron in the percarbonate treatment indicated that the transition metals could also be involved as activators of the oxidation process. The increase in the $\mathrm{Fe}^{2+} / \mathrm{H}_{2} \mathrm{O}_{2}$ weight ratio, from $0.1 / 1$ to $0.3 / 1$, increased the removal of the contaminants from $58.0 \pm 0.03$ to $80.8 \pm 4.3 \%$, respectively. Thus, it was important to optimise not only the hydrogen peroxide/ contaminant ratio but also the hydrogen peroxide/ transition metal activator ratio for effective contaminant degradation with either carrier of hydrogen peroxide.

In spite of the fact that a supplemental ferrous iron addition could improve the degradation of the contaminants with both carriers of $\mathrm{H}_{2} \mathrm{O}_{2}$ applying certain ratio of contaminant $/ \mathrm{H}_{2} \mathrm{O}_{2} / \mathrm{Fe}^{2+}$, the enhancement of the treatment efficacy was more obvious with the liquid hydrogen peroxide (Figs 2a and 2b). The addition of supplementary ferrous iron to the liquid hydrogen peroxide resulted in a higher removal of all 

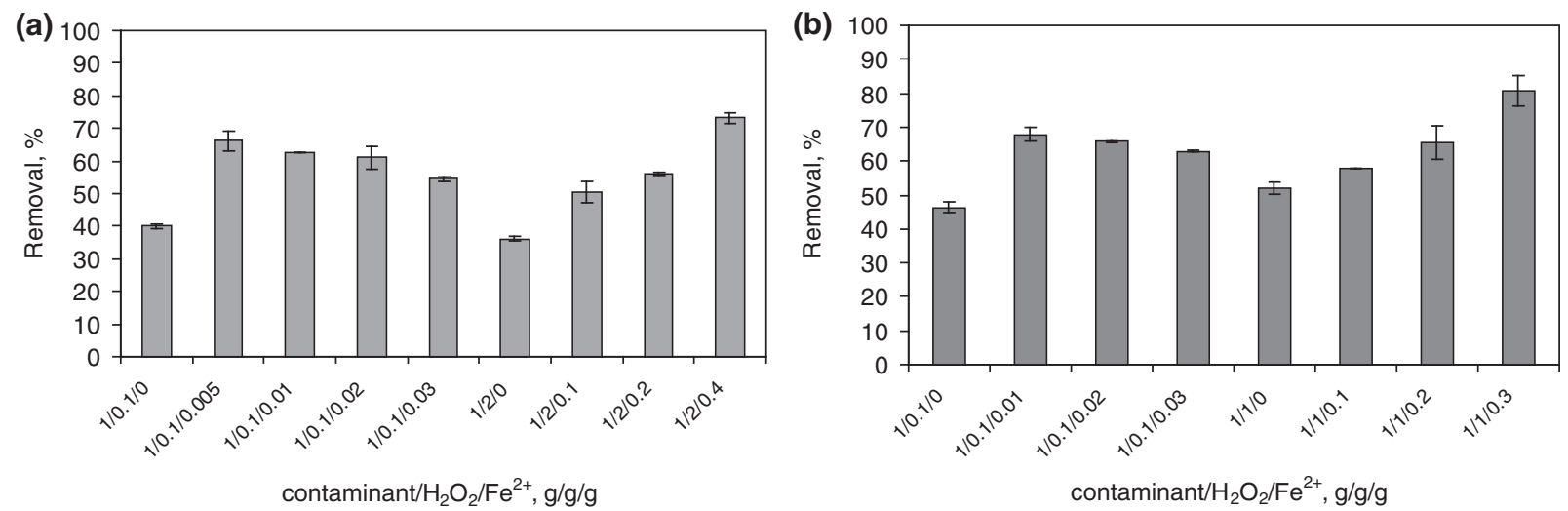

Fig. 2. Total contaminant removal ( $\%$ of initial content) in the soil after a 24-h treatment with a) hydrogen peroxide and b) percarbonate, with and without the addition of supplemental ferrous iron, at different weight ratios of contaminant-to- $\mathrm{H}_{2} \mathrm{O}_{2}$. The error bars represent the standard deviation of the replicates $(n=3)$

the target compounds compared to that obtained with a single chemical application (Figs 1 and 3). For example, while the removal of p-DCB, p-C-m-Cr and $\mathrm{p}-\mathrm{CTh}$ with the treatment involving liquid hydrogen peroxide supplemented by a ferrous iron addition was $15-18 \%, 9-10 \%$ and $31-35 \%$, respectively (Fig. 3), the removal of $\mathrm{p}-\mathrm{DCB}, \mathrm{p}-\mathrm{C}-\mathrm{m}-\mathrm{Cr}$ and $\mathrm{p}-\mathrm{CTh}$ with the treatment involving unaccompanied liquid hydrogen peroxide averaged $10.1 \pm 0.7 \%, 5.9 \pm 0.9 \%$ and $22.7 \pm$ $0.8 \%$, respectively (Fig. 1).

Increased removal of $\mathrm{p}-\mathrm{CTh}$ obtained by the treatment with percarbonate supplemented by ferrous iron compared to that achieved by the treatment with a single chemical was noted only. The soil treatment with percarbonate supplemented by ferrous iron allowed for the removal of $47-55 \%$ of $\mathrm{p}-\mathrm{CTh}$, depending on the chemical dosages used (Fig. 3). The removal of p-CTh with the treatment involving unaccompanied liquid hydrogen peroxide (soil/ $\mathrm{H}_{2} \mathrm{O}_{2}=1 / 0.0004, \mathrm{~g} / \mathrm{g}$ ) averaged $30 \%$ (Fig. 1). On the other hand, the percarbonate application supplemented by ferrous iron showed decreased removal of p-DCB and no influence on the

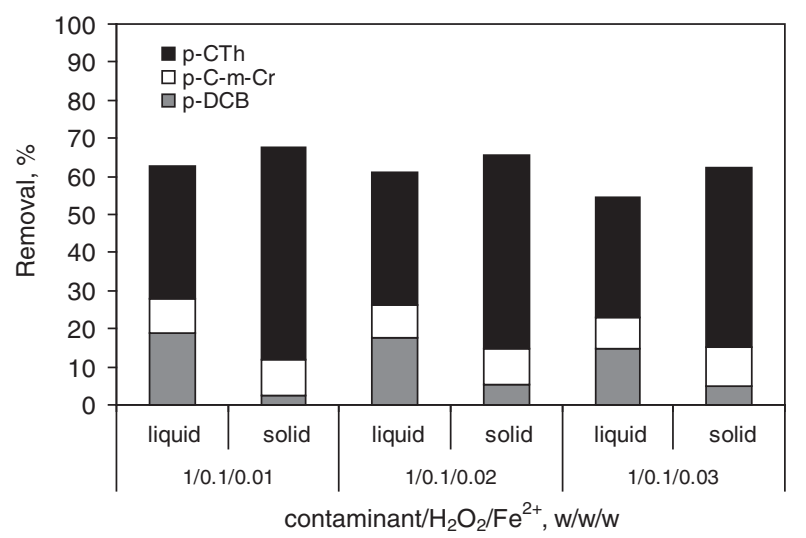

Fig. 3. p-DCB, p-C-m-Cr, p-CTh removal (\% of initial content) in the soil after $24 \mathrm{~h}$ of treatment with liquid hydrogen peroxide and percarbonate with the addition of supplemental ferrous iron
p-C-m-Cr removal (the removal was $4-5 \%$ in both cases). While the removal of $\mathrm{p}-\mathrm{DCB}$ with a single percarbonate treatment was $11 \%$ (Fig. 1), the treatment involving the percarbonate-supplementary ferrous iron system removed only 2-4\% (Fig. 3). The rates of hydroxyl radical attack on the ring of target compound might be very different depending on the type and degree of substitution. Carbonates may also act as scavengers of the hydroxyl radicals formed in excess during the rapid decomposition of hydrogen peroxide achieved by the addition of a supplementary activator. Thus, unproductive consumption of hydroxyl radicals in side reactions (Watts, Teel 2006) could occur in place of their reaction with the specific target contaminant during the treatment of soil with percarbonate supplemented by ferrous iron. This can result in p-DCB degradation decrease with the addition of supplementary ferrous iron system. Ferrous iron also has had no activation effects in a past study by Cravotto et al. (2007) during the percarbonate treatment of 4-chloronaphthol, 2,4-dibromophenol, 2,4-dichlorophenoxyacetic acid and p-nonylphenol contaminated soil.

Thus, the improvement in contaminants total degradation with supplemental ferrous iron addition was more substantial during the treatment with liquid hydrogen peroxide (Figs 2a, b) than with the percarbonate. Lower enhancement in the treatment efficacy with percarbonate could also have occurred because the ferrous iron activation efficacy could be substantially reduced due to the $\mathrm{pH}$ increase (Table 3 ) achieved during the soil treatment with percarbonate. It is known (Sylva 1972) that the Fenton reaction rate tends to decrease as $\mathrm{pH}$ increases due to the hydrolysis of iron depending on counter ion, ionic strength, and total iron concentration, culminating in the precipitation of amorphous ferric oxyhydroxides. Thus, the application of a soluble ferrous iron as an activation aid was more effective for the oxidation system utilising liquid hydrogen peroxide. 
The results for the soil slurry $\mathrm{pH}$ values measured after a 24-h treatment with either liquid hydrogen peroxide or percarbonate are presented in Table 3. The application of a lower dosage of hydrogen peroxide (contaminant $/ \mathrm{H}_{2} \mathrm{O}_{2}=1 / 0.1, \mathrm{~g} / \mathrm{g}$ ) did not influence the soil's $\mathrm{pH}$. The soil's buffering capacity was usually sufficient to offer resistance to $\mathrm{pH}$ changes during the decomposition of hydrogen peroxide applied in moderate dosages. However, the treatments with elevated hydrogen peroxide and/or activator dosages have been found capable (Liang et al. 2008) of exceeding the buffering capacity of soil. As Table 3 shows, the decrease in soil $\mathrm{pH}$ was achieved during the treatment with a twenty-fold increase in the hydrogen peroxide dosage (weight ratio of contaminant $/ \mathrm{H}_{2} \mathrm{O}_{2}$ changed from $1 / 0.1$ to $1 / 2$ ). A slightly higher decrease in $\mathrm{pH}$, due to the presence of sulphate ions from $\mathrm{FeSO}_{4}$ dissociation, was observed in the experiments involving the addition of a ferrous iron activator. The increased $\mathrm{SO}_{4}^{2-}$ concentration $\left(130-250 \mathrm{mg} \mathrm{SO}{ }_{4}^{2-} \mathrm{L}^{-1}\right.$ of the soil filtrate depending on the added ferrous iron sulphate dosage) in comparison with initial value (40 $\mathrm{mg} \mathrm{SO}_{4}^{2-} \mathrm{L}^{-1}$ of the soil filtrate) was detected in the soil filtrate after the treatment with a supplementary ferrous iron system. On the other hand, the $\mathrm{pH}$ of the soil slurry after the treatment with a solid hydrogen peroxide carrier, percarbonate, increased substantially and was greater during the application of higher dosages of percarbonate. A supplementary ferrous iron addition slightly reduced the $\mathrm{pH}$ from that achieved by the treatment with a single chemical.

\subsection{Influence of soil $\mathrm{pH}$ pre-acidification on the removal of contaminants with the hydrogen peroxide treatment}

The initial $\mathrm{pH}$ of the soil (Table 1) is higher than the optimum $\mathrm{pH}$ range of 2-4 identified for the chemical oxidation of chlorinated aromatics using the hydrogen peroxide oxidation process in water (Sedlak, Andren 1991; Ghaly et al. 2001). Thus, the treatment of the soil pre-acidified to a $\mathrm{pH}$ of 2.5 was tested. Such preacidification allowed for the improvement of the contaminant degradation process when using a liquid carrier of hydrogen peroxide (Fig. 4).

The reason for this improvement in contaminant degradation could be that acidic conditions sustain the solubility of natural soil metals mobilised during strong chemical oxidation conditions, involving them as the activators of the oxidation process (Villa et al. 2008; Dahnami et al. 2006). Moreover, only in acidic conditions the hydroxyl radical is predominant oxidant (Neyens, Baeyens 2003). On the contrary, the percarbonate treatment of the soil at an initial $\mathrm{pH}$ of 2.5 resulted in no improvement in the contaminant degradation. Percarbonate dissolves in water and may yield not only hydroxyl radicals but also several other oxidation species $\left(\mathrm{HCO}_{4}^{-}, \mathrm{CO}_{3}^{-\cdot}\right)$ that may be more stable at near-neutral

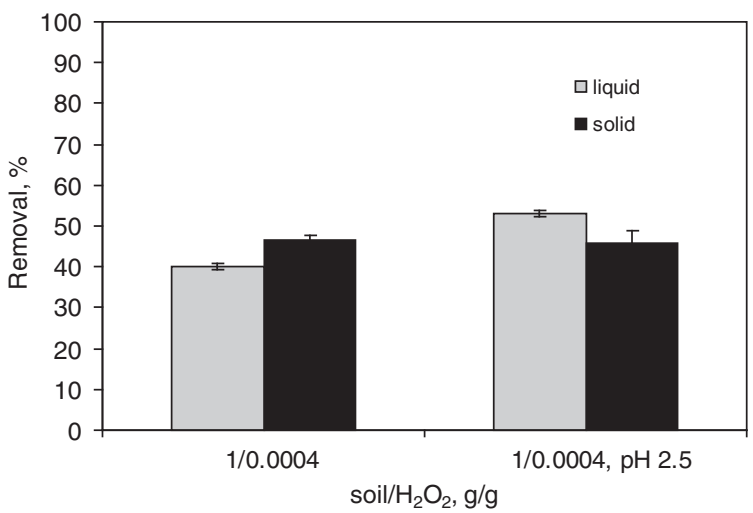

Fig. 4. Total contaminant removal ( $\%$ of initial content) in soil after $24 \mathrm{~h}$ of treatment with liquid hydrogen peroxide and percarbonate at both a natural soil $\mathrm{pH}$ and a $\mathrm{pH}$ preadjusted to 2.5. The error bars represent the standard deviation of the replicates $(n=3)$

pH values (Zuo et al. 1999; Yao, Richardson 2000; Regino, Richardson 2007). For example, in a study by Yao and Richardson (2000) on bicarbonate-activated hydrogen peroxide, a maximum catalytic efficacy for the oxidation of organic sulphides was observed at a $\mathrm{pH}$ range of 7-9.

In summary, the solid carrier of hydrogen peroxide, percarbonate, was employed as an effective alternative to the liquid carrier for the treatment of chlorinated aromatic hydrocarbon-contaminated soil, leading to a higher contaminant degradation level at natural soil $\mathrm{pH}$ values. However, further research on the chemistry of the percarbonate process and optimisation of the treatment performance will be required before full-scale treatment of contaminated soil.

\section{Conclusions}

This study performed a comparative assessment on the efficacy of using liquid and solid (percarbonate) carries of hydrogen peroxide to treat p-DCB-, CTh- and p-C$\mathrm{m}$-Cr-contaminated soil. The following conclusions were drawn from the experimental data.

1. The application of liquid hydrogen peroxide to the treatment of chlorinated aromatic hydrocarbon-contaminated soil resulted in $38 \pm 2 \%$ total removal of the contaminants, independent of the chemical dosage used. However, increasing the dosage of percarbonate increased the contaminant degradation when allowing several other reactions besides hydrogen peroxide oxidation to proceed.

2. The addition of supplementary ferrous iron increased the contaminant removal efficacy during treatment with both carriers of hydrogen peroxide. However, the improvement in contaminant degradation was more substantial during the treatment with liquid hydrogen peroxide. 
3. Pre-acidifying the soil to a $\mathrm{pH}$ of 2.5 increased the contaminant degradation during the treatment involving liquid hydrogen peroxide, but did not influence the treatment efficacy of the percarbonate.

4. The results of this study showed that percarbonate could be utilised as an effective alternative to hydrogen peroxide for the treatment of chlorinated aromatic hydrocarbon-contaminated soil at natural soil $\mathrm{pH}$ values.

\section{Acknowledgments}

The financial support of the Estonian Research Council (project JUT 1-7) and the Estonian Science Foundation (grant ETF7812) is gratefully acknowledged. We would like to thank MSc degree student Jevgenia Malinina for the experimental assistance.

\section{References}

Arienzo, M. 2000. Degradation of 2,4,6-trinitrotoluene in water and soil slurry utilizing a calcium peroxide compound, Chemosphere 40: 331-337. http://dx.doi.org/10.1016/S0045-6535(99)00212-X

Barb, W. G.; Baxendale, J. H.; George, P.; Hargrave, K. R. 1951. Reactions of ferrous and ferric ions with hydrogen peroxide. Part I. The ferrous ion reaction, Transactions of the Faraday Society 47: 462-500. http://dx.doi.org/10.1039/tf9514700462

Baxendale, J. H.; Wilson, J. A. 1957. The photolysis of hydrogen peroxide at high light intensities, Transactions of the Faraday Society 53: 344-356. http://dx.doi.org/10.1039/tf9575300344

Cravotto, G.; Carlo, S. D.; Ondruschka, B.; Tumiatti, V.; Roggero, C. M. 2007. Decontamination of soil containing POPs by the combined action of solid Fenton-like reagents and microwaves, Chemosphere 69: 1326-1329. http://dx.doi.org/10.1016/j.chemosphere.2007.05.078

Dahnami, M. A.; Huang, K.; Hoag, G. 2006. Sodium persulfate oxidation for the remediation of chlorinated solvents (USEPA Superfond Innovative Technology Evaluation Program), Water Air and Soil Pollution 6: 127-141. http://dx.doi.org/10.1007/s11267-005-9002-5

Duong, P. T.; Shrestha, R. A.; Sillanpää, M.; Virkutyte, J. 2010. Ultrasound-assisted treatment of kaolin artificially contaminated with phenanthrene, fluoranthene and hexachlorobenzene, Journal of Environmental Engineering and Landscape Management 18: 251-258. http://dx.doi.org/10.3846/jeelm.2010.29

Eisenberg, G. M. 1943. Colorimetric determination of hydrogen peroxide, Industrial \& Engineering Chemical Research 15: 327-328.

EPA Method 9045C 1995. Soil and Waste $p H$ [online], [cited 15 April 2012]. Available from Internet: http://www.epa. gov

Flangan, J.; Jones, D. P.; Griffith, W. P.; Skapski, A. C.; West, A. P. 1986. On the existence of peroxocarbonates in aqueous solution, Journal of the Chemical Society,
Chemical Communications 1: 20-21. http://dx.doi.org/10.1039/c39860000020

Feidieker, D.; Kampfer, P.; Dott, W. 1994. Microbiological and chemical evaluation of a site contaminated with chlorinated aromatic compounds and hexachlorocyclohexanes, FEMS Microbiology Ecology 15: 265-278. http://dx.doi.org/10.1111/j.1574-6941.1994.tb00250.x

Finizio, A., Vighi, M., Sandroni, D. 1997. Determination of n-octanol/water partition coefficient (Kow) of pesticide, Chemosphere 34: 131-161. http://dx.doi.org/10.1016/S0045-6535(96)00355-4

Ghaly, M. Y.; Härtel, G.; Mayer, R.; Haseneder, R. 2001. Photochemical oxidation of p-chlorophenol by $\mathrm{UV} / \mathrm{H}_{2} \mathrm{O}_{2}$ and photo-Fenton process. A comparative study, Water Management 21: 41-47. http://dx.doi.org/10.1016/S0956-053X(00)00070-2

Glaze, W. H.; Lay, Y.; Kang, J. W. 1995. Advanced oxidation processes: a kinetic model for the oxidation of 1,2dibromo-3-chloropropane in water by the combination of hydrogen and UV radiation, Industrial \& Engineering Chemical Research 34: 2314-2323. http://dx.doi.org/10.1021/ie00046a013

Goi, A; Viisimaa, M.; Trapido, M.; Munter, R., 2011. Polychlorinated biphenyls-containing electrical insulating oil contaminated soil treatment with calcium and magnesium peroxides, Chemosphere 82: 1196-1201. http://dx.doi.org/10.1016

Gomez-Belinchon, J. I.; Grimalt, J. O.; Albaiges, J. 1991. Volatile organic compounds in two polluted rivers in Barcelona (Catalonia, Spain), Water Research 25: 577589. http://dx.doi.org/10.1016/0043-1354(91)90130-I

Heron, G.; Christensen, T. H.; Tjell, J. C. 1994. Oxidation capacity of aquifer sediments, Environmental Science and Technology 28: 153-158. http://dx.doi.org/10.1021/es00050a021

Howard, P. H.; Meylan, W. M.; Fake, F. F. 1997. Handbook of physical properties of organic chemicals. 1st ed. Boca Raton: CRC Press/Lewis Publishers.

Jan, J.; Zupancic, K. L.; Kralj, B.; Marsel, J. 1994. The influence of exposure time and transportation routes on the pattern of organochlorines in plants from a polluted region, Chemosphere 29: 1603-1610. http://dx.doi.org/10.1016/0045-6535(94)90308-5

ISO 14235 1998. Soil quality - determination of organic carbon by sulfochromic oxidation. International Organization for Standardization, Geneva, Switzerland.

ISO 14688-1 2002. Geotechnical investigation and testing identification and classification of soil. Part 1: identification and description. International Organization for Standardization, Geneva, Switzerland.

ISO 14688-2 2004. Geotechnical investigation and testing identification and classification of soil. Part 2: principles for a classification. International Organization for Standardization, Geneva, Switzerland.

Kong, S.-H.; Watts, R. J.; Choi, J.-H. 1998. Treatment of petroleum-contaminated soils using iron mineral catalyzed hydrogen peroxide, Chemosphere 37: 1473-1482. http://dx.doi.org/10.1016/S0045-6535(98)00137-4 
Kot-Wasik, A.; Dezbska, J.; Namiesnik, K.; Pacyna, J. 2003. Physical, chemical, and biological changes in the gulf of Gdansk ecosystem (Southern Baltic Sea), Reviews of Environmental Contamination and Toxicology 179: 1-36. http://dx.doi.org/10.1007/0-387-21731-2_1

Ku, Y.; Su, W. J.; Shen, Y. S. 1996. Decomposition kinetics of ozone in aqueous solution, Industrial \& Engineering Chemistry Research 35: 3369-3374. http://dx.doi.org/10.1021/ie9503959

Liang, C.; Lee, I.-L.; Hsu, I.-Y.; Liang, C.-P.; Lin, Y.-L. 2008. Persulfate oxidation of trichloroethylene with and without iron activation in porous media, Chemosphere 70: 426435. http://dx.doi.org/10.1016/j.chemosphere.2007-06.077

Mackay, D.; Boethling, R. S. 2000. Handbook of property estimations methods for chemicals: environmental and health sciences. New York, USA: CRC Press.

Matta, R.; Hanna, K.; Kone, T.; Chiron, S. 2008. Oxidation of 2,4,6-trinitrotoluene in the presence of different ironbearing minerals at neutral $\mathrm{pH}$, Chemical Engineering Journal 144: 453-458. http://dx.doi.org/10.1016/j.cej.2008.07.013

McKillop, A.; Sanderson, W. R. 1995. Sodium perforate and sodium per carbonate: cheap, safe and versatile oxidizing agents for organic synthesis, Tetrahedron 51: 6145-6166. http://dx.doi.org/10.1016/0040-4020(95)00304-Q

Merck, E. 1974. The testing of water. 19th ed. Merck, Darmstadt.

Miller, C. M.; Valentine, R. L. 1999. Mechanistic studies of surface catalyzed $\mathrm{H}_{2} \mathrm{O}_{2}$ decomposition and contaminant degradation in the presence of sand, Water Research 33: 2805-2816. http://dx.doi.org/10.1016/S0043-1354(98)00500-4

Neyens, E.; Baeyens, J. 2003. A review of classic Fenton's peroxidation as an advanced oxidation technique, Journal of Hazardous Materials 98: 33-50. http://dx.doi.org/10.1016/S0304-3894(02)00282-0

Northup, A.; Cassidy, D. 2008. Calcium peroxide $\left(\mathrm{CaO}_{2}\right)$ for use in modified Fenton chemistry, Journal of Hazardous Materials 152: 1164-1170. http://dx.doi.org/10.1016/j.jhazmat.2007.07.096

Regino, C. A.; Richardson, D. E. 2007. Bicarbonate-catalyzed hydrogen peroxide oxidation of cysteine and related thiols, Inorganica Chimica Acta 360: 3971-3977. http://dx.doi.org/10.1016/j.ica.2007.05.020

Rivas, F. J.; Gimeno, O.; Borralho, T.; Carbajao, M. 2010. UV-C radiation based methods for aqueous metoprolol elimination, Journal of Hazardous Materials 179: 357362. http://dx.doi.org/10.1016/j.jhazmat.2010.03.013

Sedlak, D. L.; Andren, A. W. 1991. Oxidation of chlorobenzene with Fenton's reagent, Environmental Science and Technology 25: 777-782.

http://dx.doi.org/10.1021/es00016a024

Sun, J.; Pignatello, J. J. 1992. Chemical treatment of pesticide wastes. Evaluation of $\mathrm{Fe}(\mathrm{III})$ chelates for catalytic hydrogen peroxide oxidation of 2,4-D at circumneutral $\mathrm{pH}$, Journal of Agricultural and Food Chemistry 40: 322327. http://dx.doi.org/10.1021/jf00014a031

Sylva, R. N. 1972. The hydrolysis of iron (III), Reviews of Pure and Applied Chemistry 22: 115-130.
Teel, A. L.; Warberg, C. R.; Atkinson, D. A.; Watts, R. J. 2001. Comparison of mineral and soluble iron Fenton's catalysts for the treatment of trichloroethylene, Water Research 35: 977-984. http://dx.doi.org/10.1016/S0043-1354(00)00332-8

Tessier, A.; Campbell, P. G. C.; Bisson, M. 1979. Sequential extraction procedure for the speciation of particulate trace metals, Analytical Chemistry 51: 844-851. http://dx.doi.org/10.1021/ac50043a017

Umschlag, T.; Hermann, H. 1999. The carbonate radical $\left(\mathrm{HCO}_{3}{ }^{\circ} / \mathrm{CO}_{3}^{-}\right)$as a reactive intermediate in water chemistry: kinetics and modelling, Acta Hydrochimica et Hydrobiologica 27: 214-222.

http://dx.doi.org/10.1002/(SICI)1521-401X(199907)27:42 14::AID-AHEH2143.0.C O;2-6

Vesper, S. J.; Lawrence, C. M.; Hayes, S.; Davis-Hoover, W. J. 1994. Solid oxygen source for bioremediation in subsurface soils, Journal of Hazardous Materials 36: 265-274. http://dx.doi.org/10.1016/0304-3894(94)85019-4

Vicente, F.; Rosas, J. M.; Santos, A.; Romero, A. 2011. Improvement soil remediation by using stabilizers and chelating agents in a Fenton-like process, Chemical Engineering Journal 172: 689-697. http://dx.doi.org/10.1016/j.cej.2011.06.036

Villa, R. D.; Trovó, A. G.; Nogueira, R. F. P. 2008. Environmental implications of soil remediation using the Fenton process, Chemosphere 71: 43-50. http://dx.doi.org/10.1016/j.chemosphere.2007.10.043

Wilfried, P. 2005. Directory of microbicides for the protection of materials. A handbook. Netherlands: Springer-Verlag.

Watts, R. J.; Udell, M. D.; Leung, S. W. 1992. Treatment of contaminated soils using catalysed hydrogen peroxide. Chemical Oxidation Technologies for the Nineties, Lancaster: WA Technomic Publishing Company.

Watts, R. J.; Jones, A. P.; Chen, P.-H.; Kenny, A. 1997. Mineral-catalyzed Fenton-like oxidation of sorbed chlorobenzenes, Water Environment Research 69: 269-275. http://dx.doi.org/10.2175/106143097X125443

Watts, R. J.; Foget, M. K.; Kong, S. H.; Teel, A. L. 1999. Hydrogen peroxide decomposition in model subsurface systems, Journal of Hazardous Materials 69: 229-243. http://dx.doi.org/10.1016/S0304-3894(99)00114-4

Watts, R. J.; Teel, A. L. 2006. Treatment of contaminated soils and groundwater using ISCO, Practice Periodical of Hazardous, Toxic, and Radioactive Waste Management 10: 2-9. http://dx.doi.org/10.1061/(ASCE)1090-025X(2006)10:1(2)

Watts, R. J.; Haeri-McCarroll, T. M.; Teel, A. L. 2008. Effect of contaminant hydrophobicity in the treatment of contaminated soils by catalyzed $\mathrm{H}_{2} \mathrm{O}_{2}$ propagations (modified Fenton's reagent), Journal of Advanced Oxidation Technologies 11: 354-361.

Xu, A.; Li, X.; Xiong, H.; Yin, G. 2011. Efficient degradation of organic pollutants in aqueous solution with bicarbonate-activated hydrogen peroxide, Chemosphere 82: 1190-1195. http://dx.doi.org/10.1016/j.chemosphere.2010.11.066

Yao, H.; Richardson, D. E. 2000. Epoxidation of alkenes with bicarbonate-activated hydrogen peroxide, Journal of 
American Chemical Society 122: 3220-3221. http://dx.doi.org/10.1021/ja993935s

Zuo, Z.; Cai, Z.; Katsumura, Y.; Chitose, N.; Muroya, Y. 1999. Reinvestigation of the acid-base equilibrium of the (bi)carbonate radical and $\mathrm{pH}$ dependence of its reactivity with inorganic reactants, Radiation Physics and Chemistry 55: 15-23.

http://dx.doi.org/10.1016/S0969-806X(98)00308-9
Žukauskaitè, A.; Jakubauskaitè, V.; Ambrazaitienè, D.; Zabukas, V.; Paulauskienè, T. 2012. The impact of chemical additives on the process of biodegradation of oil products, Journal of Environmental Engineering and Landscape Management 20: 17-26. http://dx.doi.org/10.3846/16486897.2011.633336

Marika VIISIMAA. Doctoral Student, MSc (chemical and environmental technology, 2010), is the author of 17 scientific publications, 4 of which are ISI Web of Science Publications. Viisimaa underwent research training in the field of soil remediation in Finland and is currently involved in the implementation of several projects on soil remediation and wastewater purification in Estonia. Research interests: chemical treatment of soil, modified Fenton treatment of wastewater.

Anna GOI. Senior Research Scientist, PhD (chemistry and chemical engineering, 2005). Dr Anna Goi is the author of over 70 publications, 21 of which are ISI WEB of Science Publications. Research interests: advanced oxidation processes, combined chemicalbiological treatment of soil, wastewater treatment. 